\title{
Catechol and Noradrenaline Facilitate the Neuromuscular Transmission via Different Mechanisms
}

\author{
Takashi MAENo \\ Department of Physiology, Shimane Medical University, \\ Izumo, Shimane, 693 Japan
}

\begin{abstract}
Summary Using curarized frog sartorius muscles, selective presynaptic facilitatory effects of two structurally related chemicals, noradrenaline (NA) and catechol (pyrocatechol, PC), were compared by calculating the fractional release $(P)$ from the rundown of endplate potential during a train-of-three stimulation. Below $10 \mu \mathrm{M}$, both NA and PC increased $P$ in a similar manner. At higher concentrations, however, the effects of NA were found to be quite different from those of PC. NA never increased further the value of $P(0.11-0.13)$ whereas $P C$ augmented $P$ in a dose dependent fashion up to about 0.76 . Thus, the present data suggested that NA and PC facilitate the transmitter release via different mechanisms. The effects of the latter were identical to the case of "chemical potentiation or accelerated evoked release" by 4-aminopyridine.
\end{abstract}

Key Words: catechol, noradrenaline, transmitter release.

Hydroxylated benzenes such as catechol (pyrocatechol, PC) and phenol are known to possess a profound facilitatory effect on neuromuscular transmission (Coppée, 1943; Otsuka and Nonomura, 1963; Blaber and Gallagher, 1971; GALLAGHER and BLABER, 1973). The site of action of PC seems to be the presynaptic terminal, since it increases both the quantal content of endplate potentials (EPPs) and the frequency of miniature endplate potentials (mEPPs) without altering the amplitude of the mEPPs (GALlaGHer and BlABER, 1973). Similarly, micromolar doses of noradrenaline (NA) and other sympathomimetic amines that stimulate $\alpha$-adrenoreceptors have been reported to potentiate the amplitude of the EPP and increase the frequency of mEPPs (KRNJEVIĆ and MiLEDI, 1958; JENKINSON et al., 1968; KuBA, 1970; KuBA and TomitA, 1971). In the case of NA, the target of action was ascribed to be the presynaptic terminal, since the postsynaptic parameters of neuromuscular transmission were not affected (JENKINSON et al., 1968; KubA, 1970).

Received for publication December 9, 1982

前野 巍 
Table 1. Effects of micromolar doses of NA and PC on the fractional release $(P)$.

\begin{tabular}{lcccc}
\hline \multirow{2}{*}{ Test drugs } & \multicolumn{4}{c}{ Concentrations $(\mu \mathrm{M})$} \\
& 1 & 2 & 5 & 10 \\
\hline Noradrenaline & - & $1.03 \pm 0.04$ & $1.09 \pm 0.07$ & $1.21 \pm 0.07$ \\
Catechol & $1.12 \pm 0.09$ & $1.27 \pm 0.07$ & $1.69 \pm 0.18$ & - \\
\hline
\end{tabular}

NA and PC data were obtained from the same muscle in the following sequence: control-NA-washout (2nd control)-PC. To normalize the data, all the figures were expressed in test/control ratio. The concentration of Ca was adjusted to $10 \mathrm{~mm}$. Average \pm standard deviation on 6 measurements.

PC seems to act on receptors other than $\alpha$-adrenoreceptors (BLABER and GALlAGHER, 1971). However, since NA and PC have a related molecular structure and a common facilitatory drug action, it might be expected that they modify the same process in the transmitter releasing mechanism. Indeed, NA and PC were reported to stimulate the activities of $\mathrm{Na}^{+}, \mathrm{K}^{+}$-ATPase and $\mathrm{Mg}^{2+}$-ATPase in the synaptosomes of rat cerebral cortex (SAWAS and GILBERT, 1981). To elucidate whether NA and PC, in fact, interact with the same process in the excitation-secretion coupling, their facilitatory actions were compared by calculating the fractional release $(P)$ (MAENo et al., 1981). The EPPs were recorded from curarized sartorius muscles of the frog, Rana nigromaculata. Three stimuli of $0.1-0.3 \mathrm{sec}$ intervals were applied to the nerve fiber. $P$ was computed from the following formula where $P_{t}$ is the apparent fractional release, and $V_{0}$ and $V_{t}$ are the amplitudes of the first and second EPP responses in a train, respectively:

$$
P_{t}=\left(V_{0}-V_{t}\right) / V_{0} \text {. }
$$

$P_{t}$ is an exponential function of the stimulus interval $(t)$; namely $P_{t}=P \mathrm{e}^{-k t}$ (MAENo et al., 1981). When $t$ is small $(e . g .0 .1-0.3 \mathrm{sec}) \mathrm{e}^{-k t}$ can be approximated to unity, and we obtain $P_{t}=P$. Consequently, we are able to estimate a fairly accurate value of $P$. It has already been shown by MAENo et al. (1981) that $P$ serves as a useful index in analyzing the transmitter output. The amount of $d$-tubocurarine (dTC) in each test solution was adjusted so that the first EPP in a train was of almost the same amplitude in a series of experiment. Drugs used were $l$-noradrenaline bitartarate (Wako), pyrocatechol (Wako), and $d$-tubocurarine (Wako).

At micromolar doses (below $10 \mu \mathrm{M}$ ), NA and PC have been reported to increase the amplitude of EPP (Otsuka and NonOMURA, 1963; Jenkinson et al., 1968; Kuba, 1970; Gallagher and Blaber, 1973). In the present experiments, this was found to be associated with an acceleration of the rundown of EPPs (Table 1). The dose-release relation of the two drugs looked as if they were in parallel; PC had about a six times stronger effect than NA. However, at higher concentrations PC modified the transmitter release quite differently from NA (Fig. 1A). The effect of PC on $P$ was more pronounced than that of NA which was small over a wide range of concentrations (10 $\mu \mathrm{M}$ to $1 \mathrm{mM})$. 

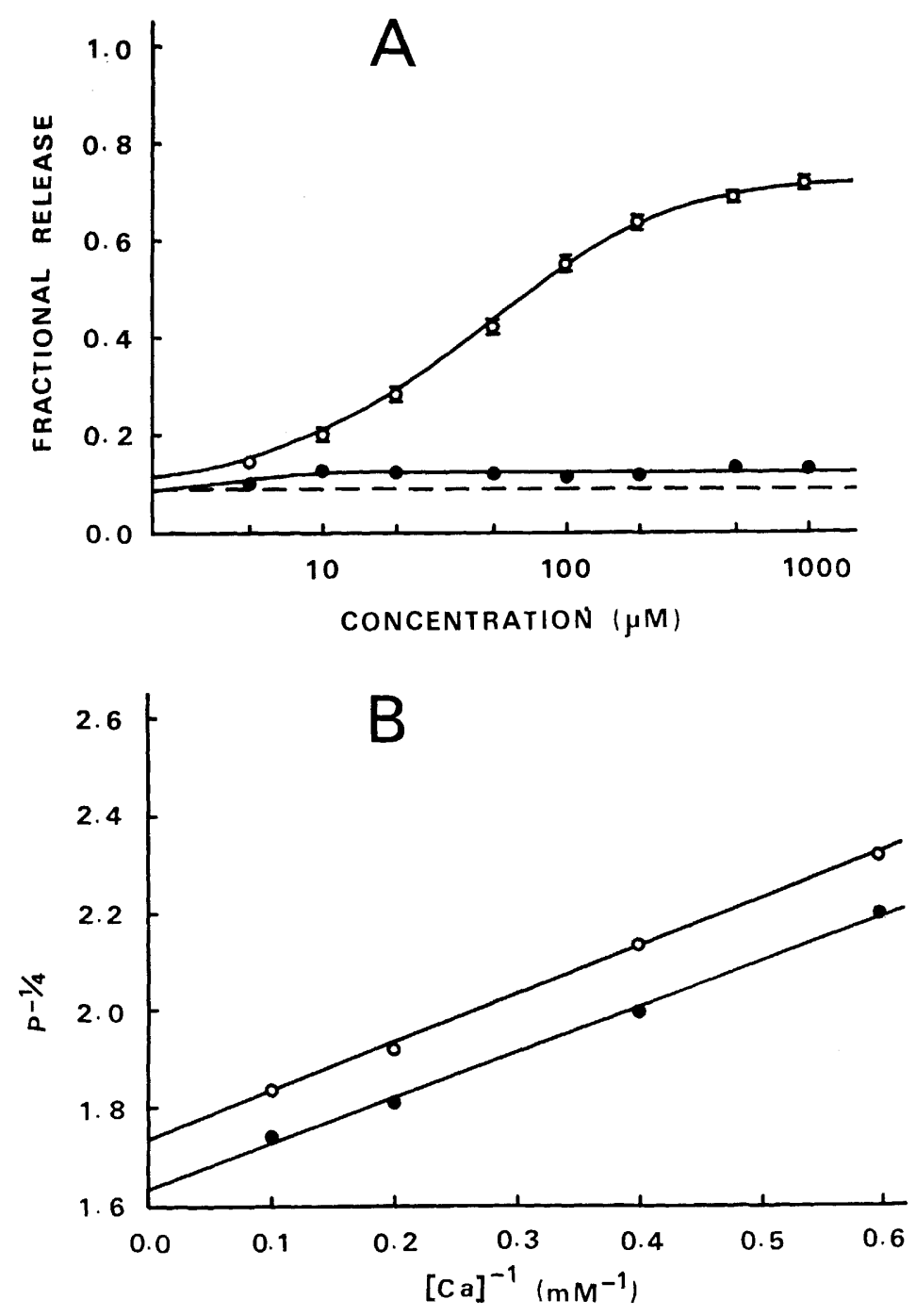

Fig. 1. A: dose-release curves of NA (filled circles) and PC (open circles). Fitted curve for PC was calculated from the equation (MAENo et al., 1981) with the following fixed parameters: $[\mathrm{Ca}]=10 \mathrm{mM}, K_{\mathrm{A}}=35 \mu \mathrm{M}, K_{\mathrm{Ca}}=0.6 \mathrm{mM}, P_{\mathrm{A}}=0.76$, and $P_{\mathrm{Ca}}=0.11$. The data for PC were averages on 6 measurements, but the data for NA were from a single muscle. The vertical bar shows standard error of the mean. Dotted line gives the level of control $P$. B: modified Lineweaver-Burk plot of the NA data. Because of fourth power relation between the transmitter output and the external $\mathrm{Ca}$ concentration, we can expect a linear relation between $P^{-1 / 4}$ and $[\mathrm{Ca}]^{-1}$. Open circles, control; filled circles, in $50 \mu \mathrm{M} \mathrm{NA}$. $P_{\mathrm{Ca}}$ was estimated graphically from the intercept on $Y$-axis to be 0.11 for control and 0.14 for $50 \mu \mathrm{M} \mathrm{NA}$. However, $K_{\mathrm{Ca}}$ calculated from the intercept on $X$-axis remained unaltered $(0.57 \mathrm{~mm})$. Averages of 7 and 5 measurements in control and $50 \mu \mathrm{M} \mathrm{NA}$, respectively. 
It should be pointed out that the pharmacological dose-release relationship of PC obtained in the present paper is identical in many respects to the case of "chemical potentiation or accelerated evoked release" (Katz and Miledi, 1979; MaEno et al., 1981) of 4-aminopyridine (4AP). The amount of dTC required to suppress the EPP potentiated by $1 \mathrm{mM}$ PC $(55-75 \mu \mathrm{M})$ was comparable to that of $1 \mathrm{~mm}$ 4AP $(66-75 \mu \mathrm{M})$. Such an enormous potentiation with PC was associated with a prolongation of the nerve terminal action potential (Maeno, unpublished) as seen with 4AP (ENOMOTo and MAENo, 1981). However, the two drugs did not alter the time course of extracellularly recorded endplate currents. The hypothetical equation proposed to explain the presynaptic action of 4AP (MAENO et al., 1981) could also be applied in the present case of PC. Furthermore, the antagonistic interaction of streptomycin (SM) on the dose-release relation of PC (Maeno, unpublished) was the same as that observed with 4AP (MAENo et al., 1981). However, peculiar multiple EPP responses seen in the presence of 4AP (LUNDH, 1978; MAENo et al., 1981) or tetraethylammonium (TEA) (KoKeTsU, 1958; MAENo et al., 1982) were rarely recorded in PC-Ringer. Relatively slow development of facilitatory presynaptic effect found with PC (15-30 min to reach the quasiequilibrium state) suggested that PC acts intracellularly as does 4AP. It might be concluded from these analogies that $\mathrm{PC}$ is a chemical potentiator or accelerator equivalent to $4 \mathrm{AP}$.

Contrarily, considerable discrepancies in the presynaptic effects have been noted between NA and the release accelerators such as 4AP, PC, and TEA. While accelerators all prolonged the nerve terminal action potential and synaptic delay (Molgó et al., 1977; Maeno, unpublished), NA was devoid of such actions (KUBA, 1970). NA manifested its effect via $\alpha$-adrenoreceptor (KUBA, 1970) whereas PC did not act at this receptor (BLABER and Gallagher, 1971). Finally, direct stimulation of the nerve terminal in the presence of tetrodotoxin clearly disclosed an important difference between the actions of accelerators and NA. The accelerators markedly increased the transmitter output by extending upward the stimulus intensity versus EPP amplitude relation (LUNDH, 1978). On the contrary, NA simply shifted the intensity-EPP curve to the left (KuBA and TOMITA, 1971). These suggest that NA does not act as an accelerator.

To explain the action of chemicals which accelerate remarkably the tetanic rundown of EPPs, MAENO et al. (1981) have postulated two types of evoked release of transmitter. Under ordinary conditions, the transmitter output is proportional to the amount of $\mathrm{Ca}$-bound $\mathrm{X}\left(\mathrm{Ca}_{4} \mathrm{X}\right)$; i. e.

$$
4 \mathrm{Ca}+\mathrm{X} \stackrel{K_{\mathrm{Ca}}}{\rightleftharpoons} \mathrm{Ca}_{4} \mathrm{X} \stackrel{P_{\mathrm{Ca}}}{\rightleftharpoons} \text { regular evoked release, }
$$

where $K_{\mathrm{Ca}}$ is the dissociation constant of $\mathrm{Ca}$ and $P_{\mathrm{Ca}}$ is the maximal $P$ anticipated when all Xs are saturated with Ca. The analysis of NA actions by KUBA and Tомтт (1971) strongly suggests that NA modulates the regular evoked release; NA increases $P_{\mathrm{Ca}}$ without affecting $K_{\mathrm{Ca}}$. This was confirmed by studying $\mathrm{Ca}$ 
versus release relationship in the present paper. As shown in Fig. 1B, modified Lineweaver-Burk plot of the $\mathrm{Ca}$ data made it clear that low level potentiation of the EPP with $50 \mu \mathrm{M}$ NA was attributed entirely to corresponding increase in $P_{\mathrm{Ca}}$ from 0.11 to 0.14 ; the value of $K_{\mathrm{Ca}}(0.57 \mathrm{~mm})$ remained unaltered. On the other hand, both the apparent $K_{\mathrm{Ca}}$ and $P_{\mathrm{Ca}}$ were found to increase in the cases of $4 \mathrm{AP}$ and PC.

By combining with $\mathrm{Ca}_{4} \mathrm{X}$, accelerator (A) such as $4 \mathrm{AP}$ and $\mathrm{PC}$ enhances the efficacy of transmitter release resulting in profound augmentation of the parameter of evoked release from $P_{\mathrm{Ca}}$ to $P_{\mathrm{A}}$;

$$
\mathrm{A}+\mathrm{Ca}_{4} \mathrm{X} \stackrel{K_{\mathrm{A}}}{\rightleftharpoons} \mathrm{A} \cdot \mathrm{Ca}_{4} \mathrm{X} \stackrel{P_{\mathrm{A}}}{\rightleftharpoons} \text { accelerated evoked release, }
$$

where $K_{\mathrm{A}}$ is the dissociation constant of A. Although Lineweaver-Burk plot of the PC data yields a linear relation, that of the NA data is independent of the NA concentration over a wide range $\left([\mathrm{NA}]^{-1}=1-100 \mathrm{~mm}^{-1}\right)$. This suggests that the presynaptic action of NA cannot be explained from the above scheme. The accelerated evoked release by PC found in the present paper $\left(K_{\mathrm{A}}=35 \mu \mathrm{M}\right.$ and $P_{\mathrm{A}}=$ $0.76)$ was somewhat less than that of $4 \mathrm{AP}\left(K_{\mathrm{A}}=8.5 \mu \mathrm{M}\right.$ and $P_{\mathrm{A}}=0.92$ : MAENO et al., 1981), but it was considerably more potent than TEA $\left(K_{\mathrm{A}}=0.5 \mathrm{mM}\right.$ and $P_{\mathrm{A}}=0.90$ : MAENo et al., 1982). Thus, the present data reveal that measurement of the fractional release provides an important clue in determining the mechanisms of actions of various release modifying agents.

\section{REFERENCES}

Blaber, L. C. and Gallagher, J. P. (1971) The facilitatory effects of catechol and phenol at the neuromuscular junction of the cat. Neuropharmacology, 10:153-159.

CoppéE, G. (1943) La transmission neuro-musculaire: Curarisation, décurarisation et renforcement à la jonction myo-neurale. Arch. Int. Physiol., 53: 327-507.

Enomoto, K. and MAeno, T. (1981) Presynaptic effects of 4-aminopyridine and streptomycin on the neuromuscular junction. Eur. J. Pharmacol., 76: 1-8.

Gallagher, J. P. and Blaber, L. C. (1973) Catechol, a facilitatory drug that demonstrates only a prejunctional site of action. J. Pharmacol. Exp. Ther., 184: 129-135.

Jenkinson, D. H., Stamenović, B. A., and Whitaker, B. D. L. (1968) The effect of noradrenaline on the end-plate potential in twitch fibres of the frog. J. Physiol. (Lond.), 195: $743-754$.

KATZ, B. and MiLedi, R. (1979) Estimates of quantal content during 'chemical potentiation' of transmitter release. Proc. $R$. Soc. Lond. (Biol.), 205: 369-378.

KoKeTSU, K. (1958) Action of tetraethylammonium chloride on neuromuscular transmission in frogs. Am. J. Physiol., 193: 213-218.

KRNJEVIĆ, K. and MiLedi, R. (1958) Some effects produced by adrenaline upon neuromuscular propagation in rats. J. Physiol. (Lond.), 141: 291-304.

KubA, K. (1970) Effects of catecholamines on the neuromuscular junction in the rat diaphragm. J. Physiol. (Lond.), 211 : 551-570.

Kuba, K, and Tomrta, T. (1971) Noradrenaline action on nerve terminal in the rat diaphragm. J. Physiol. (Lond.), 217 : 19-31.

LUNDH, H. (1978) Effects of 4-aminopyridine on neuromuscular transmission. Brain Res., 
153: 307-318.

Maeno, T., Enomoto, K., and IChinose, M. (1982) Kinetic analysis of the effect of tetraethylammonium on the neuromuscular transmission in the frog. Jpn. J. Physiol., 32: 727740.

Maeno, T., Enomoto, K., and Sawada, M. (1981) Kinetic analysis of the action of chemical modulators on neuromuscular transmission. Jpn. J. Physiol., 31: 639-656.

Molgó, J., Lemeignan, M., and Lechat, P. (1977) Effects of 4-aminopyridine at the frog neuromuscular junction. J. Pharmacol. Exp. Ther., 203: 653-663.

OtsukA, M. and Nonomura, Y. (1963) The action of phenolic substances on motor nerve endings. J. Pharmacol. Exp. Ther., 140: 41-45.

SawAS, A. H. and Gilbert, J. C. (1981) Effects of adrenergic agonists and antagonists and of the catechol nucleus on the $\mathrm{Na}^{+}, \mathrm{K}^{+}$-ATPase and $\mathrm{Mg}^{2+}$-ATPase activities of synaptosomes. Biochem. Pharmacol., 30: 1799-1803. 